MATEC Web of Conferences 44, 02004 (2016)

DOI: $10.1051 /$ matecconf/20164402004

(C) Owned by the authors, published by EDP Sciences, 2016

\title{
One kind of wind energy storage pattern and corresponding equipment
}

\author{
Zhong Ying Yuan ${ }^{1, a}$, Yan Ping $\mathrm{Li}^{2, \mathrm{~b}}$ \\ ${ }^{1,2}$ Liaoning Institute of Science and Mechanical Engineering, Liaoning Institute of Science and Engineering Practice Center, 117004 Benxi \\ City, Liaoning Province, China
}

\begin{abstract}
This paper introduced one kind of energy transformation pattern, which can be applied to oceans and their peripheral area. With this pattern, nature wind energy can be collected, transformed and stored in order to be released continuously and turned into productivity. We described the implementation plan and corresponding equipment in detail, and gave out the results of experiment system.
\end{abstract}

Keywords: Wind energy transformation; Water level promoting; Storing pattern

\section{Introduction}

Natural wind power generation is one of the main forms of wind power utilization. Though wind energy has high conversion efficiency, it is difficult to be stored in long-term or large capacity and has limitations in application. This paper describes a long-term, large capacity storage pattern of natural wind energy which can release the energy intensively and continuously in order to make full use of natural resources and promote productivity development.

Wind energy storage is consisted of wind energy collection, conversion and storage. In the surrounding areas of rivers, lakes and seas, we can use wind as power and put multi-level wind pumps and reservoirs in series on the same tower to form a multi-stage water hoist tower. Then we can transfer raised level water to higher reservoirs through pipes in order to realize the energy transformation from wind energy to water potential energy and store the energy in the form of water potential energy. We can define this process as one kind of wind energy storage pattern. The advantage of this pattern is that it can store natural wind power in long-term and large capacity, and procedures don't need electricity support, working staff. It can operate automatically and make full use of wind energy and natural resources such as rivers, lakes and seas.

\section{System equipment}

\subsection{Wind energy collection device}

Wind energy collection device is consisted of the wind deflector (Figure 1) which is rotated to be mounted on the side fixed axis of the wind dump. Wind deflector can tracking wind direction and collecting wind energy. It can receive wind energy effectively and is consisted of symmetrical flared duct is rotating with fixed axis. Wind deflector is made of thin-wall materials and is in the

\footnotetext{
a Zhongying Yuan: $\underline{\text { lkyyzy@126.com }}$

${ }^{b}$ Yanping Li: liyanping_1962@sina.com
}

This is an Open Access article distributed under the terms of the Creative Commons Attribution License 4.0, which permits unrestricted use distribution, and reproduction in any medium, provided the original work is properly cited. 
shape of a symmetrical duct which is intermediate thin and gradually turning thicker on both sides. The axis section of deflector is a symmetrical flaring curve which contains collecting energy segment and diffusion segment. The air flow can come in from the collecting energy segment and come out from diffusion segment via orifice.

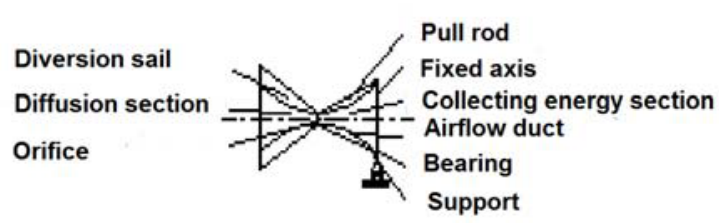

Figure 1.The cutaway view of wind deflector device

Since the pore size of the orifice is the smallest, flow rate of the fluid at the orifice is high with a small pressure and at the ends of both funnels, flow rate of the fluid is low with strong pressure. The airflow introduced into funnel sucks air flow into funnel, lets it flow towards orifice and keep it circulating. In this way, funnel can increase the flow rate and collect wind energy. Let us define the diameter of orifice is $d$, then the diameter of the end of funnels is $2 d \sim 3 d$, the distance between orifice and the end of funnels is $2 \mathrm{~d} \sim 4 \mathrm{~d}$, the flow rate at orifice is 2 3 times as that at the ends of funnels and acceptance ratio of wind energy is increased $3 \sim 5$ times. We set a fixed axis through the circle point of the ends of funnels and vertically to the ground. The axis is connected with the rotating part of funnels and its bottom is connected with main support. In order to guarantee the intensity, stiffness and stability of funnels, we set a pair of pull rods in the vertical direction on the surface of funnels. One side of the pull rods is connected with funnels and the other side is connected with the outer edges of each bearings. Apart from the function that it can support funnels, the axis also has the function to track wind direction in order to guarantee that the ends of funnels are always towards the direction of airflow and keep the funnels always work on the perfect direction. In order to make the funnels can track wind direction more reliable, we set a pair of contra-vanes in the vertical direction on the surface of the diffusion segment of funnels. Then we put wind wheel for wind energy acceptance device near the orifice of diffusion segment. Hence, we can decrease both radial dimension of the rotating part of wind wheel and manufacturing costs of wind energy machines.
What's more, It can track wind direction automatically, collect wind energy and always keep the wind acceptance device towards the right direction in order to accept and collect wind energy more effectively.

\subsection{Wind energy conversion devices}

Usage of a multi-stage wind pump and an impounding reservoir in series so as to constitute a high-stand hoist tower, can realize the transformation from wind energy to high-stand potential energy. Wind pumps take usage of wind energy guiding device, and take natural wind as driving force. Wind pumps consist of reciprocating pumps driven by wind wheels and mechanical drive group. A wind pump can be divided into three parts: wind receiver, transmission mechanism and reciprocating pumps.

Wind receiver: With the wind energy guiding device, the three-wing wind turbine is installed in the orifices of the wind energy guiding device which is near diffuser segment side, and the wind wheel is connected by the rotation of the horizontal drive shaft coupled with the duct. The combination of a duct and a wind wheel consist of the wind receiver, which can transform wind energy into rotational mechanical energy of the wind wheel.

Transmission mechanism: the output of the horizontal drive shaft is connected idly with the vertical drive shaft which is covered by the fixed axis. And the vertical drive shaft, the lower end of the wind duct as well as the fixed axis connected rigidly are rotatably connected, while the output of the vertical drive shaft is mounted on the main stand by horizontally rotating the other bevel gear and axis and the output of the vertical drive shaft as well meshing transmitted with driving bevel gear set in the vertical plane. There is a hinge axis fixed off center in the drive shaft. One side of connecting rod is rotatably connected with drive shaft via hinge axis and the other side is connected with the piston which can reciprocate in vertical direction in the reciprocating pump. The axis is rotatably connected with vertical drive shaft on the same axis and permalink to the main support which is fixed on the ground.

Reciprocating pumps: It is installed under the water level and is consisted of cylinder block, piston which can reciprocate in vertical direction and one-way flow tubes 
for influent and effluent, which is set at the bottom of cylinder block and connected with lower plenum. Reciprocating pumps is rotatably connected with drivers via connecting rods and use the driving forces from connecting rods to change the water pressure in the sealed lower plenum which is under the piston. The change can make water flowing and rise the water level and finish the pumping operation.

Because of the combination of wind pumps and wind deflector, wind wheel is always in the best direction and can efficiently receive and utilize wind energy.

\subsection{Reservoir water level automatic control device (Figure 2)}

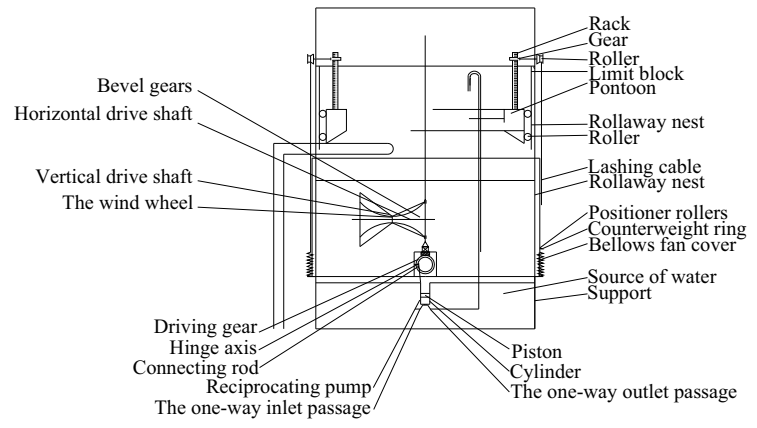

Figure 2.The operating principle diagram of the wind power water pump and the automatic control device of reservoir water level

Water level automatic control device is a feedback signal equipment which uses a hollow box in reservoir, which can produce buoyancy to drive workload or lock executive devices. It is consisted of the support, reservoir, pontoon, transmission components and air bellows covers. Top bracket is mounted with reservoir, central is installed with wind pumps and the lowermost part is water supply sources. Support is a cylindrical building which is vertical to horizon ground and has four uprights uniformly set on the surface. The water level in the reservoir is relied on the water flow from the inlet and outlet. This equipment can limit the water level by controlling the water flow from inlet. The water flow from inlet is relied on working condition of wind pump which is under the reservoir. And the working condition of wind pump is relied on the current airflow in the wind deflector. If the airflow is small, the displacement is small;
If the airflow is large, the displacement is large. Hence, the displacement is proportional to airflow in the wind deflector. In this way, the water level of reservoir can be controlled by controlling the airflow in the wind deflector. The current water level can be defined as a feedback signal and transferred to the executive devices. Then we can build a closed feedback system ${ }^{[1]}$.

The detail plan is: We put a sealed hollow ring buoyancy tank which has idler wheels and is defined as that it can only move on vertical direction. Top bracket is fixed symmetrically with four groups of racks in the vertical direction. The racks are meshing with wheel gears which is horizontal radial installed and is on the idler wheel which is rotatably connected with support via the same axis. The digging line of the idler wheel is fixed with heavy ring which is fixed with top bracket of bellow wind covers. There are four positioner rollers rotatably connected with heavy ring. Part of positioner rollers are in the rollway nest of support in the vertical direction. The idler wheel and rollway nest form the vertical track of bellow wind covers. The water level of reservoir is controlled within the scales which are decided by the stop blocks on the support. When the water level is higher than the lower stop block, buoyancy tank can make bellow wind cover moving upward by drivers in order to decrease effective airflow in wind deflector and also displacement of wind pump. When the water level is up to the upper stop block, the bellow wind cover will block air vent of the pump and the pump will stop working. Then the water level can be raised. Reservoir water level automatic control device is realized by mechanical linkage without electricity. The structure is quite easy and has safety in operation. It is also easy to install and repair $^{[2]}$.

\subsection{Water potential energy storage device}

Water potential energy storage device is consisted of high reservoirs which have the same height or are higher than the multi-stage hoist tower. High reservoirs(Figure 3) have large capacity. Based on theory of communicating vessels, the water flow can automatically move from high-level hoist tower to high reservoirs. In this way, the energy can be stored as water potential energy and released continuously and turned into productivity for 


\section{MATEC Web of Conferences}

better society. The high water flow from high reservoir can be used to generate electricity heating, irrigation or build urban and rural water pipe network. The stage of high-level hoist tower are set based on the needed water level and the maximum water $\operatorname{lift}^{[3]}$.

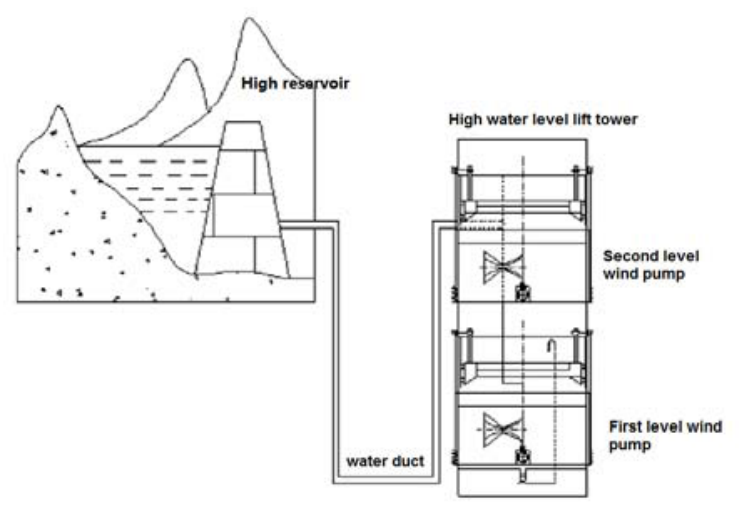

Figure 3.Wind energy storage model and corresponding operating principle diagram

\section{Epilogue}

Wind deflector can automatically set the inlet in the right direction in real time and effectively gather wind energy to orifice. The wind wheels in the orifice can receive wind energy and transform it to mechanical energy by making reciprocating pumps working with drivers. Then the mechanical energy can be transformed to water pressure to push the water flow to each reservoirs and water pressure can be transformed to water potential energy and stored in reservoir. Each wind pumps moves the water flow towards the highest reservoir for storage, then the tubes transfer the water flow to high reservoir and the energy can be stored in the form of high water potential energy ${ }^{[4]}$.

In the spring, we put two wind pumps in series as a 2-stage hoist tower for experiment at the waterfront of Donggang City. After thirty days operation, the experiment can raise $3600 \mathrm{~m}^{3}$ sea water to $36 \mathrm{~m}$ height under the condition that the average wind force is level four, the area of wind mouth of the wind pumps is $32 \mathrm{~m}^{2}$ and the height of the hoist tower is $36 \mathrm{~m}$. The experiment system can work automatically without staff and the process is stable and reliable.

\section{References}

[1] J.Sheng. Hydro-mechanics, China Machine

Press, (1980)

[2] M.Shi. EST,5,18-22(2000)

[3] X.Yong, JAP, 13,49-52(1998)

[4] Z.Du, AESS, 21, 364-370(2000) 